\title{
Perceptions of elementary teachers about physical activity breaks in the classroom
}

\author{
P. Constantinides ${ }^{{ }^{*}}$, D. Constantinidou ${ }^{\text {a }}$ \\ a Department of Education, Frederick University, Nicosia 1036, Cyprus \\ *Corresponding author Ph: 00357-99987485 E-mail: panosc22@gmail.com \\ DOI: https://doi.org/10.34256/ijpefs2136 \\ Received: 16-05-2021, Revised: 16-07-2021; Accepted: 20-07-2021; Published: 25-07-2021
}

\begin{abstract}
The purpose of this study was to explore classroom teachers' perceptions in providing physical activity breaks during their regular lessons in their classrooms. Twenty-two randomly selected school teachers (6 men and 16 women) from public urban elementary schools participated in this study. Data collection took place in the participating school settings during regular school time and included 30-minute semi-structured interviews, teachers' reflective journals and field notes taken for classroom facilities, number of students in each class, available space in each class, etc. Data were analyzed inductively by conducting a systematic search for similar patterns that occurred across the collected data. According to the results, teachers identified barriers to implementation of activity breaks, such as a) had a hard time for class management when movement activities were included, b) did not have a minimum repertoire of activities to implement in class, c) had limited pedagogical knowledge in implementing the activity breaks, d) had difficulties in re-starting the class, e) had a limitation of time, due to the additional workload, beyond their regular teaching load in class and other school responsibilities and f) had limited space to implement physical activity breaks in the classroom. As far as the content, results showed that teachers prefer activity breaks relevant to the lesson, enjoyable to students, or waking up students to attend the rest of the lesson effectively. These findings may have practical implications regarding physical education teacher education and professional development for classroom teachers.
\end{abstract}

Keywords: Activity breaks, Classroom teachers, Elementary school, Obesity

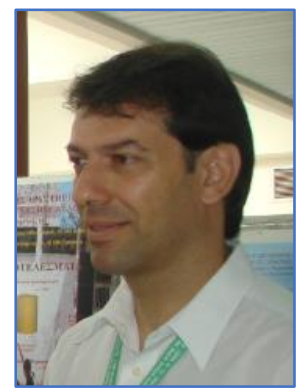

Dr. Panos Constantinides is an Assistant Professor of Curriculum and Teaching in Physical Education in the Department of Education at Frederick University in Cyprus and the Coordinator of the "Physical Education \& Sport Science Program". Previously, he has worked for Brooklyn Hospital, New York, for City University of New York, at all levels of Education (preschool-high school) and others. He has published textbooks and research papers in International Journals and has presented numerous research papers at International Conferences. He has designed and developed bachelor, master, and vocational programs of study for Frederick University. In addition, he is a reviewer in international research journals, and he's affiliated with international associations. His teaching and research work has been recognized and awarded internationally. Dr.
Constantinides' research interests include effective teaching in Physical Education and Sports, health for a better quality of life, and physical literacy.

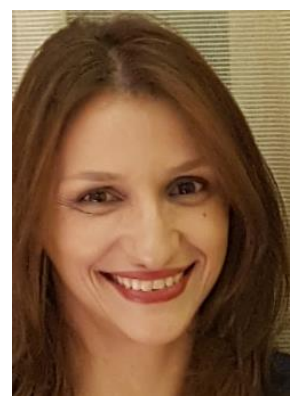

Dr. Dora Constantinidou is a Mathematics \& Statistics high school teacher, collaborating with Frederick University, doing research analyses as a statistician. She has previously worked for Keyspan Energy, New York, conducting electric load forecasting. Dr. Constantinidou has presented research papers in many international conferences and has published her work in international research journals. In addition to her teaching duties, she is preparing the school program every year. 


\section{Introduction}

Children spend approximately half of their day in schools [1], but most of the time is spent in sedentary behaviors [2]. Despite the academic pressure, schools may serve as prime opportunities to increase children's physical activity. Physical activity should not be limited to physical education and recess time. Physical education teachers or those assigned to teach this class in elementary school should not have the sole responsibility. On the contrary, classroom teachers who provide instructions in courses such as mathematics, science, reading, and writing, etc., could also provide physical activity during their regular classes to help increase student physical activity levels. International organizations such as the World Health Organization (WHO) recommend at least 60 minutes of moderate to vigorous intensity physical activity on a daily basis. Most of the daily physical activity should be aerobic, but vigorous intensity activities should be incorporated, such as those that strengthen muscle and bone, at least three times a week [3].

Despite the international guidelines [3], technology evolution leads children to use several electronic devices for a significant amount of time during the day, especially in the afternoon, becoming more sedentary. Unfortunately, an alarm is ringing the past decades and so for children in several European countries, including Cyprus, calling them to eliminate the time spent in front of the television, in front of a computer or any other electronic device, leave the cough and engage in any kind of physical activity. This is critical, considering Cyprus is ranked among the top European countries in childhood obesity $[4,5]$.

Elementary physical education, which is part of the formal curriculum in schools, is expected to contribute towards decreasing childhood obesity and increasing children's physical activity levels in schools $[6,7]$. One of the vital elements towards that is creating positive attitudes towards physical education and physical activity [8]. The benefits of regular physical activity and the knowledge, skills, and attitudes needed to lead to an active lifestyle can be taught to all children [9-11], starting from an early stage of life.

Although tons of studies worldwide refer to the health benefits that derive from physical education and regular physical activity, a number of reasons seem to negatively affect the quality of the lesson in Cypriot elementary schools: (a) the status of the class (considered as less important as opposed to other classes), (b) the importance given to other classes as opposed to physical education [12], (c) the rather negative attitudes towards physical education curried by educational leaders and stakeholders, such as principals, teachers, or parents [8], (d) little financial and human resources available to physical education, (e) the minimal support for staff development, especially for those teachers who are really interested to teach the class effectively ( $f$ ) the curriculum learning outcomes which cannot be reached in most cases [8, 12], (g) the guidelines of the curriculum reform, which took place in 2009, for more student-oriented teaching are not followed [13], (h) classroom teachers' content knowledge (CK) and pedagogical content knowledge (PCK) is limited as opposed to specialists', to teach the lesson effectively [12, 14-17] and (i) selection of common branch teachers to teach the class than specialists. Considering all these reasons, the quality of the lesson is questionable, and furthermore, the goal of developing positive attitudes towards physical education in children seems to be extremely difficult. In addition, the time spent for actual physical activity during class in Cyprus is minimal, somewhere between 10-30 minutes and 30-90 minutes per week in classes $1^{\text {st }}-4^{\text {th }}$ and $5^{\text {th }}-6^{\text {th }}$ respectively [18], indicating that international guidelines [3] are not met. Having all the above in mind, it seemed critical to investigate common branch teachers' perceptions in providing activity breaks in the classroom.

In a recent study [19], the feasibility of providing physical activity breaks in Cypriot elementary school classrooms by classroom teachers was investigated, during their regular lessons and beyond the time spent in physical education, as a first step to increasing children's physical activity involvement time. Considering that similar interventions were conducted before $[20,21]$, the author wanted to take immediate action to improve children's daily physical activity time. Indeed, classroom teachers managed to provide physical activity breaks to children during their regular classes, indicating that children's physical activity time in school may increase in that way. However, it is well known that during an intervention or a short while after that, things may look better, but then the intervention effect is fading.

In the present study, the researcher wanted to take it a step forward. Knowing that common branch teachers can provide physical activity breaks in their classes [19-21], two major questions arise: (a) What their perceptions were about providing physical activity breaks in their classrooms. (b) They had to deal with 
problems when providing these breaks, which may have inhibited providing activity breaks in class. Therefore, the purpose of the current study was to investigate classroom teachers' perceptions in delivering physical activity breaks in the classroom.

\section{Materials and Methods}

Upon learning that teachers may provide activity breaks in their classes during a previous intervention [19], the author was interested in investigating elementary teachers' perceptions on providing physical activity breaks throughout the school year. Considering that their perceptions may affect their decisions to provide these breaks, it seemed important to find out how these teachers feel about it and if this effort to increase elementary students' physical activity time would continue upon completion of this study and throughout the year. Information about the study was provided to all participants, and questions were answered about the procedure and the role of the participants upon receiving approval from the Ministry of Education and the school principals and written consent from teachers. In addition, school principals were reassured that the school's regular program would not be affected in any way during data collection.

\subsection{Participants}

The participants in this study were 22 elementary school classroom teachers ( 6 male and 16 female) from 10 urban public schools (Table 1 ). Teachers were randomly selected from elementary public schools in the capital city of Cyprus, Nicosia. Teachers were not assigned to teach physical education in their schools but other classes such as science, math, and English. Both teachers' and schools' names were coded. The purpose of the study was thoroughly explained to the participants.

\subsection{Data Collection}

Data collection included a 30-minute semistructured interview with each participating teacher, participating teachers' reflective journals, and authors' field notes for the size of the class (number of students), the available space offered in class, material in the class, type of class, etc. The interview included questions such as "What difficulties did you have to deal with when incorporating physical activity breaks in the classroom" or "What differences/similarities did you find with a regular class in management components" or "Do you connect the activity break with the content of the lesson or not."

Table 1 Participating teachers' demographics.

\begin{tabular}{|c|l|l|l|c|c|l|}
\hline S.No & Teacher & School & Gender & $\begin{array}{c}\text { Grade } \\
\text { Level }\end{array}$ & $\begin{array}{l}\text { Teaching } \\
\text { experience }\end{array}$ & Education \\
\hline 1 & Teacher 1 & School 1 & Female & 4th & 10 & Master's \\
\hline 2 & Teacher 2 & School 1 & Male & 6th & 22 & Bachelor \\
\hline 3 & Teacher 3 & School 2 & Female & 6th & 15 & Master's \\
\hline 4 & Teacher 4 & School 3 & Female & 5th & 17 & Master's \\
\hline 5 & Teacher 5 & School 4 & Female & 4th & 14 & Master's \\
\hline 6 & Teacher 6 & School 4 & Female & 5th & 19 & Master's \\
\hline 7 & Teacher 7 & School 4 & Male & 5th & 16 & Master's \\
\hline 8 & Teacher 8 & School 5 & Female & 4th & 12 & Bachelor \\
\hline 9 & Teacher 9 & School 5 & Female & 6th & 17 & Master's \\
\hline 10 & Teacher 10 & School 6 & Female & 4th & 25 & Master's \\
\hline 11 & Teacher 11 & School 6 & Female & 6th & 19 & Master's \\
\hline 12 & Teacher 12 & School 6 & Female & 4th & 21 & Master's \\
\hline 13 & Teacher 13 & School 6 & Male & 5th & 16 & Master's \\
\hline 14 & Teacher 14 & School 7 & Female & 4th & 19 & Master's \\
\hline 15 & Teacher 15 & School 7 & Female & 6th & 14 & Master's \\
\hline 16 & Teacher 16 & School 8 & Male & 5th & 18 & Bachelor \\
\hline 17 & Teacher 17 & School 8 & Male & 4th & 13 & Master's \\
\hline 18 & Teacher 18 & School 9 & Female & 5th & 23 & Master's \\
\hline 19 & Teacher 19 & School 9 & Female & 6th & 25 & Master's \\
\hline 20 & Teacher 20 & School 10 & Male & 5th & 18 & Master's \\
\hline 21 & Teacher 21 & School 10 & Female & 6th & 21 & Master's \\
\hline 22 & Teacher 22 & School 10 & Female & 5th & 15 & Master's \\
\hline
\end{tabular}


Additionally, clarification questions according to the content of each teacher's reflection journal were asked to get a better picture of each teacher's perception. Data collection took place in the participating schools without interrupting the regular school program. Meetings with teachers for the 30minute semi-structured interviews were organized according to their date and time of preference.

\section{Results and Discussion}

Targeting on increasing elementary students' physical activity time to fight the childhood obesity epidemic, this study was conducted to investigate elementary school teachers' perception in providing physical activity breaks in their classrooms. The results revealed that teachers a) had a hard time for class management when movement activities were included, b) did not have a minimum repertoire of activities to implement in class, c) had limited pedagogical knowledge in implementing the activity breaks, d) had difficulties in re-starting the lesson, e) had a limitation of time, due to the additional workload, beyond their regular teaching load in class and other school responsibilities and f) had limited space to implement physical activity breaks (Chart 1 ). The results are presented separately below.

\subsection{Class management difficulties when movement activities were included}

According to the information collected from interviews, teachers' reflection journals, and researchers' observations, classroom teachers in this study had a hard time on classroom control, when an activity break was given.
On one hand, some students would take advantage on the "kind of freedom" offered to them to move around, talk to each other and over socialize in class. On the other hand, classroom teachers who are used to manage their class when students are sitting down in a specified space without been allowed to talk unless they get permission and obviously without moving around, are called to manage the "class in motion". Class mobility seems to distract the peaceful class environment. Teachers, who are in control of their classes, are more hesitant to provide activity breaks. Instead, they prefer to work on their "safety zone", that is an environment without mobility which is easy for them to manage.

Modifying management practices in physical education to fit the classroom setting may help classroom teachers cope better [22]. Some basic management principles that could be applied in the classroom are: (1) use different start and stop signals but use them consistently (e.g., 1 whistle to start and 2 whistles to stop); (2) use "when" before "what" when giving directions (e.g., When I say go, start jumping..."); (3) organize your students efficiently (e.g., in small groups, pairs, or individually); (4) give your instructions quickly (e.g., in 30seconds or less); and (5) have the necessary equipment ready.

\subsection{Limited repertoire of activities to implement when providing activity breaks}

A physical education specialist usually carries a repertoire of activities to show in class, according to the topic of the day. A classroom teacher, however, who's not assigned to teach physical education, carries limited activities to show in class whenever needed.

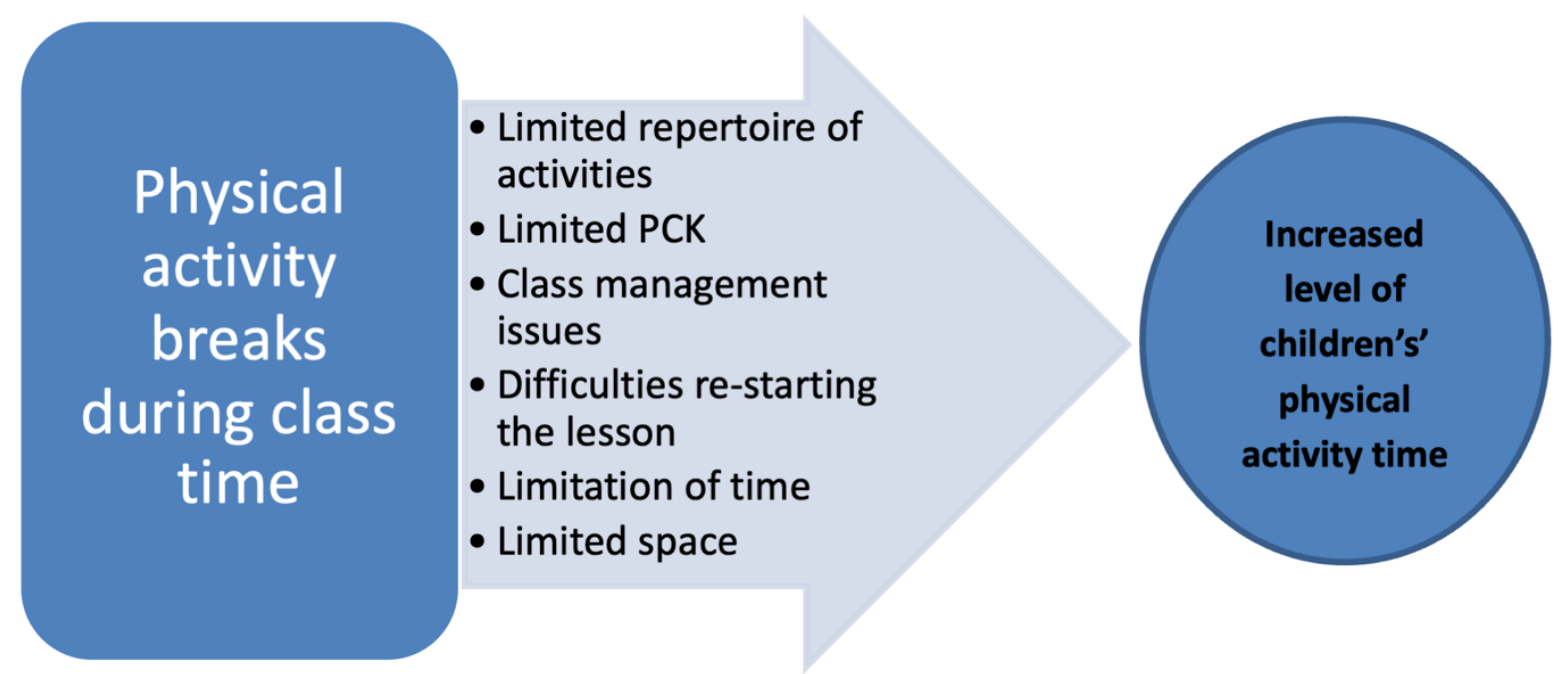

Chart 1 Difficulties when providing activity breaks in the classroom 
For the teachers in this study, that was raised as one of the major problems. During preparation for the class, teachers had to search for ideas on the internet that would match the content of the lesson, or would be appropriate to implement in class. As some of them mentioned, that was a difficult task to complete. Even more difficult than teaching a regular class, since it requires more preparation.

\subsection{Limited pedagogical content knowledge in implementing the activity breaks}

A regular classroom picture consists of students who are sitting down listening to the teacher, discussing a topic, asking questions or taking notes. Classroom teachers are educated and trained in college and prepare themselves before class on ways and practices to teach lessons such as mathematics, science or English. Pedagogical knowledge on teaching these classes could be similar, however, for an activity break, components of pedagogical content knowledge derive from physical education class, which is not a class they are assigned to teach. That makes it seem like "climbing a mountain", as one of the participating teachers mentioned.

"It's not something you do every day", another teacher stated. "When you watch an organized physical education lesson, everything seems to be easy, but I guess, that reflects on teacher's pedagogy training in teaching this specific class."

"You think it's easy, but when you try it, then you understand how much preparation you need", another teacher complied.

\subsection{Class management difficulties during the activity breaks}

Teachers in this study felt they were losing control during an activity break in the classroom. Some students would take advantage on the "kind of freedom" offered, since they were allowed to move around, talk to each other and socialize in class. That gave them the opportunity to make noise, bother other students, pretend they cannot hear teacher's comments, etc. On the other hand, classroom teachers who are used to manage their class when students are sitting down quietly, feel they are outside their "safety zone" as mentioned earlier, that is a class environment without mobility which they got used to manage all these years.

\subsection{Difficulties in re-starting the lesson}

One of the common themes that came out from this study, in line with other studies [3], was teachers' difficulty in restarting the lesson, as soon as the break was over. Teachers highlighted children's excitement for the unusual opportunity they were given to move around in class, especially when the break was connected to the course content. However, when the signal was given that the break was over, children wanted to go on for more, or were still excited, even if they were already sitting down. One teacher stated: "You tell them that the break is over and you expect them to focus on the lesson. They feel hyper, they still talk loudly and you need to put a lot of effort to get them back on track!"

\subsection{Limitation of time}

Another common theme that derived from this study was the limitation of the available classroom time. Teachers were concerned about the curriculum to be covered in all classes. Since they were assigned to teach a variety of classes, they needed class time to cover the relevant material. In addition, classroom teachers were expected to organize and implement classroom and school celebrations for Christmas, mother's day, end of the school year, etc. All these require much of the teachers' free time as well as much classroom time. With these in mind, it seems difficult to dedicate time for activity breaks. "You have to think about everything in a classroom; Student learning, school celebrations, unexpected problems that may occur. Teachers are required to do a lot, the available time, however, remains the same" one of the teachers mentioned. "You keep struggling to catch up time!" another teacher stated. "It's a challenge for a teacher! Additional tasks keep occurring by the time and you are expected to do everything well."

\subsection{Limited space for physical activity}

Elementary teachers demonstrate excessive concern about student safety, because they care about all their students and they feel responsible for them, not only for learning, but also for their wellness and health. Having that in mind makes it easy to understand why some teachers hesitate to provide activity breaks in their classes, even in situations when students seem to be very tired to follow the lesson. Teachers keep thinking: "What if a student gets hurt by a table or a chair?" The room is full of classroom furniture, which does not make it easy for any activity. "Who's going to be blamed for that?" In addition, in 
case of an injury, teachers have to report the incident and give explanation to school principals and parents, therefore, they think about it twice, before giving an activity break.

\subsection{Further discussion}

The purpose of this study was to explore elementary teachers' perceptions in providing physical activity breaks during their regular lessons in their classroom. Overall, most participating teachers in this study have struggled to implement physical activity breaks in their classrooms, although exceptions occurred. Most of them have used activity breaks that were relevant to the content of the class, with easy or more complicated activities.

According to the results, several factors may impact elementary teachers' ability to provide physical activity breaks, including time management problems, limited repertoire of activities, lack of pedagogical knowledge in implementing activity breaks, difficulties in re-starting the lesson and lack of time and space, usually, due to the additional workload, beyond their regular teaching load in class and other school responsibilities. These findings extend our knowledge of teacher's perceptions in providing activity breaks in the classroom and provide insight into what factors need to be targeted to enable teachers to use activity breaks in a regular basis.

All teachers reported lack of activity repertoire, since they were not assigned to teach activity classes, such as physical education, at school. That's reasonable, but also a limitation in providing activity breaks, in a sense that they would be able to provide activity breaks more often if they were given ideas and support from a mentor or through professional development workshops with sample lessons. This finding is in contrast to previous findings in which teachers' negative attitudes and lack of interest were barriers in offering activity breaks [23, 24].

Teachers in this study, who were athletes in the past or were currently active, were more likely to find resources to enrich their knowledge in such a degree, that would allow them to provide physical activity breaks in the classroom. Obviously, due to their positive attitude towards physical activity, they wanted to extend that to their students. Understanding the health benefits from regular physical activity, it seemed to be an important task for them in the classroom. This is similar to research findings which suggest that implementation of activity breaks in the classroom may reflect teachers' own interest in physical activity and furthermore health $[25,26]$.

The participants in this study argued that it was hard to organize activity breaks in the classroom, due to lack of available space. Most of the space in the classroom is filled in with tables, chairs and other classroom equipment, which makes elementary teachers skeptical as far as if it's safe to allow students to run, jump, etc. This might be relevant to the lack of repertoire of activities. A great number of activities do not require running or jumping and could be organized in a limited space. Classroom teachers, however, are not physical education specialists, who are trained to apply activity programs indoor or outdoor, in spacious or limited space environments [12].

One of the most crucial barriers according to elementary teachers was working overload, which usually leads to limitation of classroom time. Teachers have a lot of responsibilities from the time they enter school until they leave. These responsibilities usually include coverage of the curriculum defined by the Ministry of Education, which, on its own, is a very demanding task: Preparation of material or classrooms for different lessons, organization of material, making copies for children, patrolling in the school yard for children safety and other. Beyond that, teachers are expected to prepare and organize class and school celebrations for national days, religious days, and other occasions, making them think about it twice when asked to use class time for any other reason.

When classroom teachers are asked to teach physical activities or physical education in schools, according to the participants, the first thing that comes to their mind is that "physical education is a totally different class, as opposed to the other classes." Teachers are used to teaching in a classroom environment where student mobility is limited, the possibility of an injury is decreased and teachers have control of the class.

A common theme emerged from all the participants was their difficulty in restarting the lesson, just right after the activity break. Teachers did not want to waste class time, but students were still in an "activity mood." This is similar to what was found in a previous study [21] about restarting the lesson. Participants in this study discussed students' ability to get back on task after an activity break and the difficulty teachers had to deal with when they wanted them to sit down and continue the lesson. 
For the reasons discussed above, teachers' feel a lot of pressure. They are called to satisfy all school expectations, both academic and non-academic, which may negatively affect them using activity breaks in their classrooms [14, 25]. Even if they decide to provide activity breaks in class, management issues occur, leading to the conclusion that classroom teachers might need help broadening their management skills to be able to include activity breaks in their classes on a daily basis. Specific management skills that physical education teachers use, but classroom teachers may not be familiar with. Modifying management practices in physical education to fit the classroom setting may help classroom teachers develop, in using activity breaks [4]. Some basic management principles that could be applied in the classroom are: (1) use different start and stop signals but use them consistently (e.g., 1 whistle to start and 2 whistles to stop); (2) use "when" before "what" when giving directions (e.g., When I say go, start jumping..."); (3) organize your students efficiently (e.g., in small groups, pairs, or individually); (4) give your instructions quickly (e.g., in 30seconds or less); and (5) have the necessary equipment ready.

\section{Conclusion}

Classroom teachers have a great deal to worry about in their daily routines in the classroom; teaching content of each class they teach, student behavior, school and class celebrations and other. The last thing they want is to add more to their already demanding daily schedule. Therefore, as elementary teachers consider physical activity breaks in their classrooms, it might be important to ensure they see the implementation process as simple and worthwhile. Teaching academic content is their main priority. If activity breaks can get students moving in the classroom in a fun way and reinforce the content of the lesson, then classroom teachers might be more likely to incorporate them in their classes regularly. Suppose teachers are convinced to use activity breaks as an alternative teaching method. In that case, this may have a greater impact among teachers and may be easier accepted and implemented in their classes, contributing to kids' higher levels of physical activity.

\subsection{Implications for teachers' education and professional development}

This study demonstrated that common branch teachers would need help broadening their management skills to feel comfortable giving activity breaks during a regular school day. Previous studies revealed that providing support to classroom teachers (i.e., mentoring, professional development, etc.) may lead to the more successful implementation of physical activity included in the classroom. Providing support to teach breaks that integrate content they teach in their classes could broaden physical activity integration in elementary classrooms. Providing support during teacher education programs by demonstrating physical activity breaks to preservice teachers and allowing them to practice during their student teaching placement may encourage them to provide these activity breaks to their students during their professional years. In addition, giving sample lessons in the classroom that include activity breaks, which are quick and require minimum sources during teacher development workshops, will empower teachers and will provide ideas on activity breaks relevant to the content, which they could include in their classrooms.

\section{References}

[1] T. D. Synder, \& S.A. Dillow, (2012). Digest of education statistics 2011 (NCES2012-001). Washington, DC: National Center for Education Statistics, Institute of Education Statistics, US Department of Education. Retrieved from: https://nces.ed.gov/pubs2012/2012001.pdf

[2] R.A. Abbott, L.M. Straker, \& E.S. Mathiassen, Patterning of children's sedentary time at and away from school, Obesity, 21 (2013) 131-133. [DOI] [PubMed]

[3] A. Watson, A. Timperio, H. Brown, \& K.D. Hesketh, Process evaluation of a classroom active break (ACTI-BREAK) program for improving academic-related and physical activity outcomes for students in years 3 and 4, BMC Public Health, 19 (2019) 633. [DOI] [PubMed]

[4] G. Joseph, M. Genakritis, P. Vezyrides, \& A. Samoutis, Interventions for Childhood Obesity Controls in Cyprus: An analysis and evaluation of programmes and protocols, International Journal of Caring Sciences, 6(2) (2013) 146-169.

[5] C. Lazarou, D.B. Panagiotakos, A.L. Matalas, Children's Adherence to the Mediterranean diet in Cyprus: The CYKIDS study, Public Health Nutrition, 12(7) (2010) 991-1000. [DOI] [PubMed]

[6] K.C. Graber, L.F. Locke, D. Lambdin, \& M.A. Solmon, The landscape of elementary school physical education, The Elementary School Journal, 108(3) (2008) 151-159. [DOI] 
[7] D. Kirk, Physical education, youth sport and lifelong participation: The importance of early learning experiences, European Physical Education Review, 11(3) (2005) 239-255. [DOI]

[8] P. Constantinides, \& S. Silverman, Cypriot elementary students attitudes towards physical education, Journal of Teaching in Physical Education, 37 (2018) 69-77. [DOI]

[9] P. Constantinides, Differences in physical activity levels among students that are taught by physical education teachers and classroom teachers, Exercise \& Society, 52 (2011) 7-14.

[10] P. Constantinides, Perceptions of elementary obese students about their experiences in physical education, Physical Education \& Sport, 32(3) (2013) 89-102.

[11] J. Mandigo, Presenting the evidence: Quality physical education for Canadian children and youth position statement by Physical \& Health Education Canada, PHENex Journal, 2(1) (2010).

[12] P. Constantinides, R. Montalvo, \& S. Silverman, Teaching processes in elementary physical education classes taught by specialists and nonspecialists, Teaching and Teacher Education, 36 (2013) 68-76. [DOI]

[13] P. Constantinides, (2019). Perceptions of elementary teachers for the use of activity breaks in the classroom. Paper presented at the 20th National Conference of the Physical Education Teachers' Association of Northern Greece. Thessaloniki, Greece.

[14] M. Parks, M. Solmon, \& A. Lee, Understanding classroom teachers' perceptions of integrating physical activity: A collective efficacy perspective, Journal of Research in Childhood Education, 21(3) (2007) 316-328. [DOI]

[15] I. Rovegno, Theoretical perspectives on knowledge and learning and a student teacher's pedagogical content knowledge of dividing and sequencing subject matter, Journal of Teaching in Physical Education, 14 (1995) 284-304. [DOI]

[16] I. Rovegno, The development of in-service teachers' knowledge of a constructivist approach to physical education: Teaching beyond activities, Research Quarterly for Exercise and Sport, 69 (1998) 147-162. [DOI]

[17] I. Rovegno, (2003). Teachers' knowledge construction, in S. Silverman \& C. Ennis (Eds.), Student learning in physical education: Applying research to enhance instruction (pp. 295-310). Champaign, IL: Human Kinetics.
[18] P. Constantinides, (2015). Preservice teachers' planning and teaching elementary physical education. Can we bridge the gap? Paper presented at the 18th International Conference of the Physical Education Teachers' Association of Northern Greece. Thessaloniki, Greece

[19] P. Constantinides, Increase in elementary students' physical activity levels: The use of activity breaks, IOSR Journal of Sports and Physical Education, 7(1) (2020) 23-30. [DOI]

[20] D. Dinkel, J.M. Lee, \& C. Schaffer, Examining the knowledge and the capacity of elementary teachers to implement classroom physical activity breaks, International Electronic Journal of Physical Education, 9 (1) (2016) 182-196. Retrieved from: https://files.eric.ed.gov/fulltext/EJ1126711.pdf

[21] J. McMullen, P. Kulinna, \& D. Cothran, Physical Activity Opportunities During the School Day: Classroom Teachers' Perceptions of Using Activity Breaks in the Classroom, Journal of Teaching in Physical Education, 33 (2014) 511527. [DOI]

[22] P.H. Kulinna, M. Stylianou, K. Lorenz, J. Martin, M. Hodges, \& J. Houston, (2013). Using social cognitive theories to investigate teacher behavior change in integrating physical activity breaks. Paper presented at the American Educational Research Association 2013 annual meeting, San Francisco, California, April.

[23] K.R. Evenson, K. Ballard, G. Lee, \& A. Ammerman, Implementation of a school-based state policy to increase physical activity, Journal of School Health, 79(5) (2009) 231-238. [DOI]

[24] P.J. Morgan, \& V. Hansen, Classroom teachers' perceptions of the impact of barriers to teaching physical education on the quality of physical education programs, Research Quarterly for Exercise and Sport, 79(4) (2008) 506-516. [DOI]

[25] D.J. Cothran, P.H. Kulinna, \& A.C. Garn, Classroom teachers and physical activity integration, Teaching and Teacher Education, 26 (2010) 1381-1388. [DOI]

[26] C.A. Webster, P. Caputi, M. Perrault, R. Doan, P. Doutis, \& R.G. Weaver, Elementary classroom teachers' adoption of physical activity promotion in the context of a statewide policy: An innovation diffusion and socio-ecologic perspective, Journal of Teaching in Physical Education, 32 (2013) 419-440. [DOI] 


\section{Funding}

No funding was received for conducting this study.

\section{Authors Contribution}

Both the author equally contributed to this work. Also, both of them read and approved the final version of the manuscript.

\section{Ethics Approval}

Ethics approval sought from the Ministry of Education and the school principals.

\section{Informed Consent}

Written consent was obtained from the teachers.

\section{Conflict of interest}

The Authors have no conflicts of interest to declare that they are relevant to the content of this article.

\section{Does this article screened for similarity?}

Yes

\section{About The License}

(C) The Author(s) 2021. The text of this article is open access and licensed under a Creative Commons Attribution 4.0 International License 